\title{
Complete genome sequence of Lactobacillus plantarum SK156, a candidate vehicle for mucosal vaccine delivery
}

\author{
In-Chan Hwang, Sang Hoon Kim and Dae-Kyung Kang* \\ Department of Animal Resources Science, Dankook University, Cheonan 31116, Korea
}

Received: Aug 20, 2020

Accepted: Sep 17, 2020

*Corresponding author Dae-Kyung Kang

Department of Animal Resources

Science, Dankook University, Cheonan 31116, Korea.

Tel: +82-41-550-3655

E-mail: dkkang@dankook.ac.kr

Copyright $\odot 2020$ Korean Society of

Animal Sciences and Technology.

This is an Open Access article distributed under the terms of the Creative Commons Attribution Non-Commercial License (http:// creativecommons.org/licenses/bync/4.0/) which permits unrestricted non-commercial use, distribution, and reproduction in any medium, provided the original work is properly cited.

ORCID

In-Chan Hwang

https://orcid.org/0000-0001-8268-989X

Sang Hoon Kim

https://orcid.org/0000-0001-9811-2972

Dae-Kyung Kang

https://orcid.org/0000-0001-9241-1250

\section{Competing interests}

No potential conflict of interest relevant to this article was reported.

Funding sources

This work was supported by the National Research Foundation of Korea (NRF) grant funded by the Korea government (MSIT) (No.2020R1A2C1010406)

Acknowledgements Not applicable.

\begin{abstract}
Lactobacillus plantarum SK156 was isolated from traditional Korean food. The genome of SK156 strain consists of a circular chromosome $(3,231,383 \mathrm{bp})$ with guanine $(G)+$ cytosine (C) content of $44.56 \%$. Among the predicted 2,991 protein-coding genes, the genome included genes encoding for $\alpha$-amylase, which hydrolyzes $\alpha$-bonds of polysaccharides. Genomic sequencing of $L$. plantarum SK156 will give information on the mechanism involved in the enzymatic degradation of polysaccharides and its application for improving feed efficiency.

Keywords: Genome, Lactobacillus plantarum, a-Amylase
\end{abstract}

In our previous study, Lactobacillus plantarum SK156, originally isolated from traditional Korean food, was revealed to be an effective host for the expression of bioactive substances in the intestine [1]. The SK156 strain expressed the antigens of porcine epidemic diarrhea virus on its cell surface, which causes acute watery diarrhea in pigs, inducing both immune responses in mice following oral administration (unpublished data); these findings suggested that SK156 is a promising candidate vehicle for mucosal vaccine delivery in animals. For complete genome analysis, L. plantarum SK156 was grown in de Man, Rogosa, and Sharpe (MRS) Broth (Difco, Franklin Lakes, NJ, USA) at $37^{\circ} \mathrm{C}$ for $12 \mathrm{~h}$. Genomic DNA of SK156 strain was prepared as described previously [2] and its quality was validated using spectrophotometry (UV-1601PC, Shimadzu, Kyoto, Japan). The genomic DNA of L. plantarum SK156 was sequenced using the PacBio RSII platform ver. 2.0 (Pacific Biosciences, Menlo Park, CA, USA) at Macrogen (Seoul, Korea), and then all reads were de novo assembled using the RS HGAP Assembly ver.3.0 protocol [3]. Functional annotation was performed using the InterProScan ver. 5.30-69.0 (http:// www.ebi.ac.uk/interpro/), GO (http://geneontology.org/page/go-database), BLAST ver. 2.6.0+ (http:// blast.ncbi.nlm.nih.gov/) with UniProt ver. 2018_06 (http://www.uniprot.org/), and EggNOG ver. 4.5 (http://eggnogdb.embl.de/\#/app/home) databases. The genome of L. plantarum SK156 was submitted into GenBank (https://www.ncbi.nlm.nih.gov/) under accession no. CP059473.

The genome of SK156 strain consists of a circular chromosome (3,231,383 bp) with guanine (G) + cytosine (C) content of $44.56 \%$ (Table 1), and no plasmids were detected (Fig. 1). A total of 2,991 protein-coding sequences, 65 tRNAs and 16 rRNAs were annotated (Table 1). Genomic sequence analysis showed that SK156 possessed genes encoding for $\alpha$-amylase enzyme, which hydrolyzes $\alpha$-bonds of polysaccharides and generate malto-oligosaccharides in animal feed [4-6]. Genomic sequencing of $L$. 
Availability of data and material Upon reasonable request, the datasets of this study can be available from the corresponding author.

Authors' contributions

Conceptualization: Hwang IC, Kim SH, Kang DK.

Data curation: Kim SH

Formal analysis: Hwang IC, Kim SH.

Methodology: Hwang IC, Kim SH.

Validation: Kang DK.

Investigation: Kim SH.

Writing - original draft: Hwang IC, Kim SH Kang DK.

Writing - review \& editing: Kang DK.

Ethics approval and consent to participate This article does not require IRB/IACUC approval because there are no human and animal participants.
Table 1. Genome features of Lactobacillus plantarum SK156

\begin{tabular}{lr}
\hline \multicolumn{1}{c}{ Attribute } & Value \\
\hline Genome size (base pair) & $3,231,383$ \\
GC content (\%) & 44.56 \\
Number of contigs & 1 \\
Total genes & 3,072 \\
Protein-coding genes & 2,991 \\
tRNAs & 65 \\
rRNAs & 16 \\
\hline
\end{tabular}

GC, guanine-cytosine.

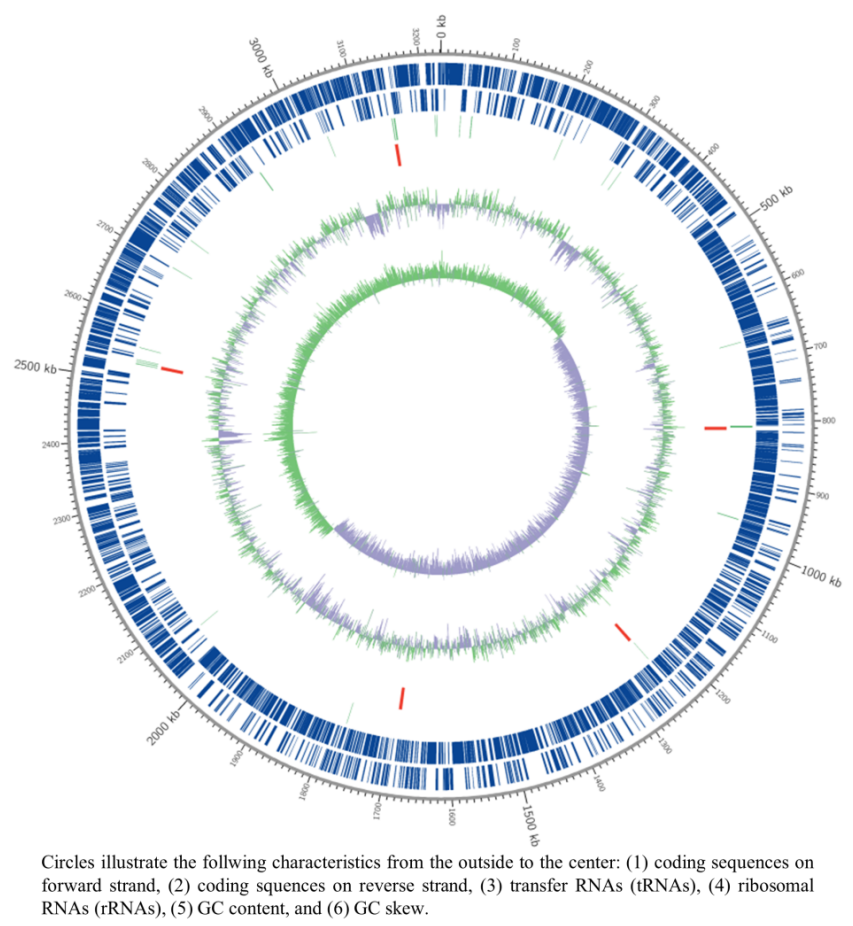

Fig. 1. Chromosome map of Lactobacillus plantarum SK156. GC, guanine-cytosine.

plantarum SK156 will give information on the mechanism involved in the enzymatic degradation of polysaccharides and its application for improving feed efficiency.

\section{REFERENCES}

1. Chae JP, Pajarillo EA, Hwang IC, Kang DK. Construction of a bile-responsive expression system in Lactobacillus plantarum. Food Sci Anim Resour. 2019;39:13-22. https://doi. org/10.5851/kosfa.2018.e58

2. Valeriano VDV, Oh JK, Bagon BB, Kim H, Kang DK. Comparative genomic analysis of Lactobacillus mucosae LM1 identifies potential niche-specific genes and pathways for gastrointestinal adaptation. Genomics. 2019;111:24-33. https://doi.org/10.1016/j.ygeno.2017.12.009

3. Chin CS, Alexander DH, Marks P, Klammer AA, Drake J, Heiner C, et al. Nonhybrid, finished microbial genome assemblies from long-read SMRT sequencing data. Nat Methods. 2013;10:563-9. https://doi.org/10.1038/nmeth.2474 
4. Sundarram A, Murthy TPK. $\alpha$-Amylase production and applications : a review. J Appl Environ Microbiol. 2014;2:166-75. https://doi.org/10.12691/jaem-2-4-10

5. Zhang Q, Han Y, Xiao H. Microbial $\alpha$-amylase: a biomolecular overview. Process Biochem. 2017;53:88-101. https://doi.org/10.1016/j.procbio.2016.11.012

6. Novakovska VY. Productivity of pigs when feeding celluloseamylolytic additive. Sci Messenger LNU Vet Med Biotechnol Ser Agric Sci. 2020;22:76-80. https://doi.org/10.32718/nvlvet-a9213 